\title{
A modified single jejunal loop reconstruction by performing proximal gastrojejunostomy after Whipple's pancreticoduodenectomy in a low-volume hospital
}

\author{
Ali Naki Yücesoy \\ General Surgery Department, Batı Bahat Hospital, Istanbul, Turkey
}

\begin{abstract}
Backgrounds/Aims: It is needed to ensure bowel and biliary tract continuity after pancreaticoduodenectomies. It is possible to find a variety of reconstruction methods in literature. Methods: We realized a modified reconstruction method by performing proximal gastrojejunostomy, on a jejunal loop after Whipple's pancreticoduodenectomy, with surgical succes in 7 patients with pancreatic head or periampullary carcinomas in a low-volume hospital 2009-2017. Results: A modified jejunal loop reconstruction method, was performed in 7 patients after Whipple's pancreaticoduodenectomy. We had no perioperative mortality. Pancreatic fistula treated with medical attempts was observed following post-operative pancreatitis in a patient. No marginal ulceration was observed. Delayed gastric emptying was not observed, except for post-operative acute pancreatitis and pancreatic fistula developing in a patient. Conclusions: A modified reconstruction method by performing proximal gastrojejunostomy on a jejunal loop, can be considered as alternative reconstructive surgical procedure after pancreaticoduodenectomy. (Ann Hepatobiliary Pancreat Surg 2019;23:65-68)
\end{abstract}

Key Words: Pancreaticoduodenectomy; Delayed gastric emptying; Marginal ulceration

\section{INTRODUCTION}

Pancreatic surgery is one of the major intraabdominal surgical attempts, due to its retroperitoneal localization and close proximity to the duodenum, stomach, spleen, colon, and intraabdominal vasculer structures. The pancreas is anatomically investigated in three parts: the head, the body, and tail. Embryologically, pancreatic tissue is formed by fusion of two separate embrionic buds. While the pancreatic head and duodenum are originated from the ventral embryonic bud, the body and tail of the pancreas are originated from the distal embrionic bud. The pancreatic head and duodenum are anatomically considered as inseparable units, and en-block pancreaticoduodenal resection is proposed for pancreatic head lesions. Non-endocrine pancreatic and periampullary carcinomas are the fourth leading cause of cancer deaths affecting both genders equally. While pancreatic cancer occurs approximately $65 \%$ in the head of the pancreas, $15 \%$ in the body and tail, and the remaining $20 \%$ show diffuse localization in the gland. ${ }^{1}$

Allen O.Whipple is considered the father of pancreaticoduodenectomy, although the first pancreaticoduodenectomy operation was performed by W. Kauch in 1912. ${ }^{2,3}$ Whipple's operation is standard surgical treatment for operable adenocarcinomas of the head of the pancreas, as well as other periampullary tumors, cholangiocarcinoma of the distal biliary tree, primary duodenal adenocarcinoma, duodenal GIST and duodenal lymphoma, and in some cases of chronic pancreatitis. Today, perioperative mortality rate reported at $20-40 \%$ during the beginning of the operation, has been reduced to $0-4 \%$ in experienced hands. Complication ratios of the operation remain high, reported at $30 \%-40 \%$, despite decreased mortality rate. Delayed gastric emptying (DGE) and pancreatic fistulae, are the most common complications observed after pancreaticoduodenectomies. Intraabdominal abscess, haemorrhage, wound infections, pancreatitis, metabolic

Received: May 24, 2018; Revised: September 28, 2018; Accepted: October 4, 2018

Comesponding author: Ali Naki Yücesoy

General Surgery Department, Batı Bahat Hospital, Atatürk mah. İkitelli Cad. No:135 K.çekmece, Istanbul, Turkey Tel: +0900 021247133 00, Fax: +09000212 4713317, E-mail: alinakiyucesoy@gmail.com

Copyright (C) 2019 by The Korean Association of Hepato-Biliary-Pancreatic Surgery

This is an Open Access article distributed under the terms of the Creative Commons Attribution Non-Commercial License (http://creativecommons.org/ licenses/by-nc/4.0) which permits unrestricted non-commercial use, distribution, and reproduction in any medium, provided the original work is properly cited. Annals of Hepato-Biliary-Pancreatic Surgery • pISSN: 2508-5778 - elSSN: 2508-5859 
disorders, and marginal ulcerations are other common complications.

\section{MATERIALS AND METHODS}

Modified reconstruction operations subsequent to pacreaticoduodenectomies were performed with right subcostal hockey incision in supine position. After abdominal exploration, patients were initially evaluated in terms of tumor resectability by mobilizing the duodenum and distal part of the stomach, until reaching the portal vein and Trietz's ligament. Operations were launched by performing of retrograde cholecystectomy, after resectability of tumors were detected. After total mobilization of the doudenum and pancreatic head until reaching Treitz's ligament and the portal vein, the jejunum was proximally divided, following gastroduodenal and distal choledochus transsections performed. Pancreaticoduodenectomy, including pancreatic head and neck, was completed by performing transsection of the pancreas at the portal vein level. After completion of pancreaticoduodenectomy, the proximal jejunum was prepared for single jejunal loop reconstruction by protecting its vascular integrity. Surgical reconstruction was performed on the jejunal loop by respectively performing pancreaticojejunostomy, gastrojejunostomy, and hepaticojejunostomy. After pancreaticojejunostomy performed by partly invaginating the remaining pancreas into the jejunum (Fig. 1), gastrojejunostomy was performed in end-to-side and pylor-preserving manner approximately $15 \mathrm{~cm}$ away from thepan-

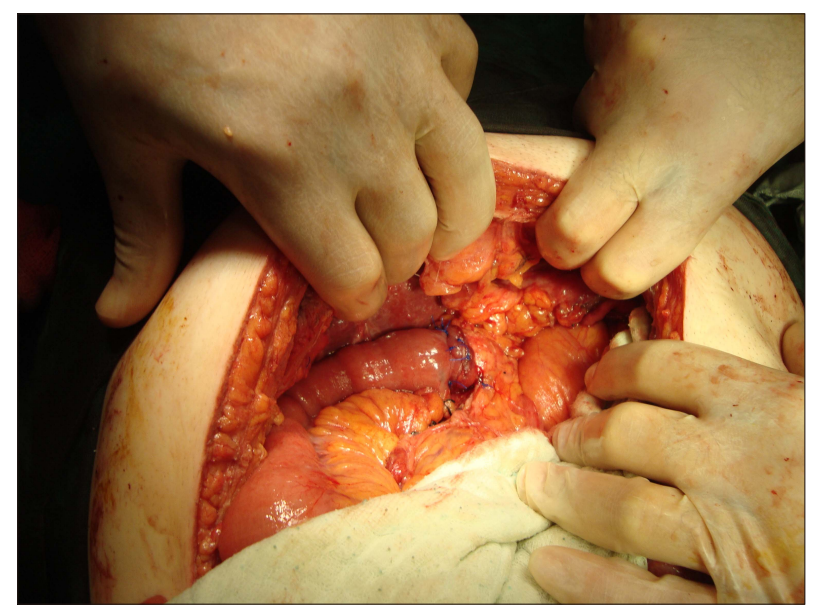

Fig. 1. End-to-end pancreaticojejunostomy by partly invaginating the remaining pancreas into the jejunum. creaticojejunostomy (Fig. 2). Hepaticojejunostomy was performed in end-to-side manner, by using interrupted one-layer sutures approximately $25 \mathrm{~cm}$ from the gastrojejunostomy, last. Operations are illustrated in Fig. 3.

\section{RESULTS}

Pancreaticoduodenectomy and modified reconstruction method on a jejunal loop, were performed in 7 patients with median age of 72 in a low-volume hospital from year 2009 to 2017. While the 3 patients had pancreatic head carcinoma, 3 patients had periampullar carcinoma, and 1 patient had chronic pancreatitis, due to the main pancreatic canal stone. While mean operation time was $210 \mathrm{mi}-$ nutes, mean hospital stay was 18 days. We had no perioperative mortality. Pancreatic fistula addressed with medical treatments that occured following post-operative acute

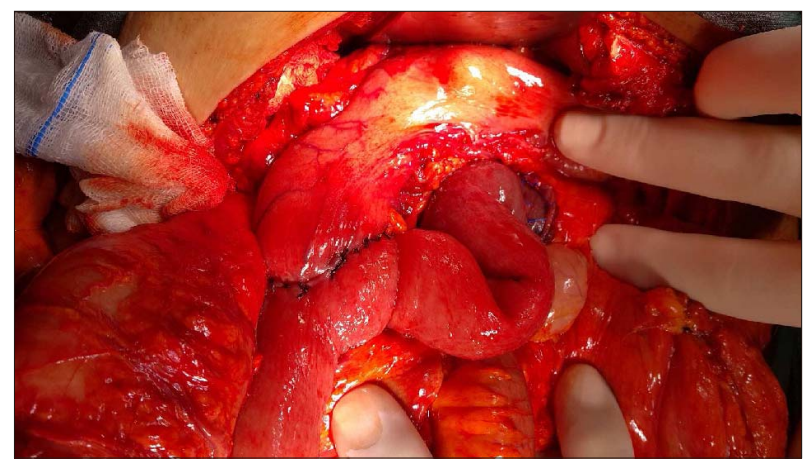

Fig. 2. Proximal gastrojejunostomy approximately $15 \mathrm{~cm}$ from pancreaticojejunostomy.

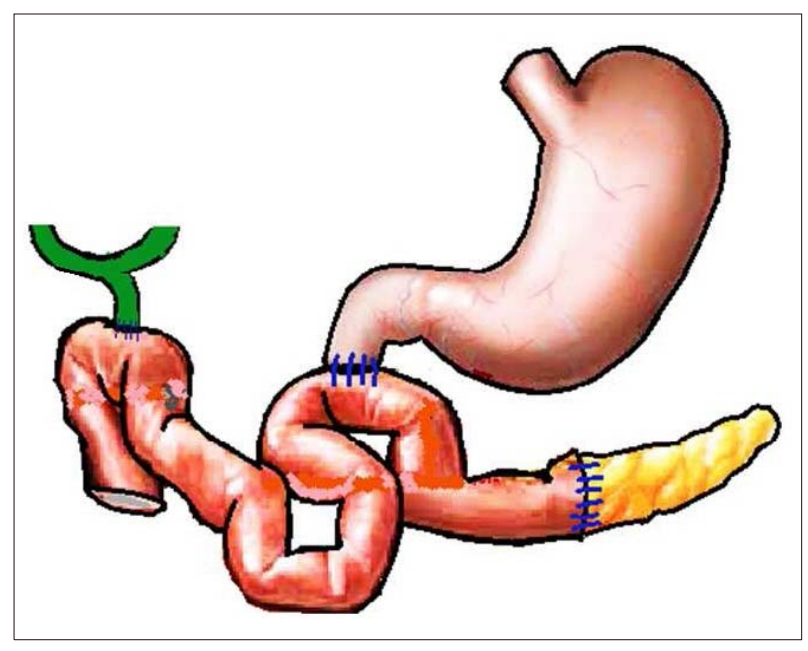

Fig. 3. Illustration of the modified single jejunal loop reconstuction by performing proximal gastrojejunostomy after Whipple's pancreaticoduodenectomy. 
pancreatitis development, was only observed in a patient as a major post-operative complication. No intra-abdominal hemorrhage or abscess was observed. Wound infection and detachment were encountered in only 1 patient. We did not encounter with DGE, when we excluded the patient treated with the cause of pancreatic fistula. No marginal ulcerations were observed in patients, in repeated gastroscopic examinations performed in their post-operative periods.

\section{DISCUSSION}

Pancreaticoduodenectomy is a spectacular surgery, commonly performed for pancreatic head and periampullary carcinomas, with high morbidity and mortality. ${ }^{4-9}$ Although post-operative mortality ratios after pancreaticoduodenectomy have been significantly reduced, post-operative complication rates remain high. DGE observed in 11\%-29\% of patients, and pancreatic fistula occurring in 5\%-20\% of patients, are the most common major post-operative complications after pancreaticoduodenectomies. Wound infection and detachment occurring in 5\%-20\% of patients, are other most common complications observed after panctreaticoduodenectomies. Abscesses occur after panctreaticoduodenectomies in approximately $10 \%$ of patients. Postoperative pancreatitis, and post-operative hemorrhage may also be encountered in $5 \%$ of patients in their post-operative periods. ${ }^{10}$

Procedures to ensure of bowel and biliary tract continuity after pancreticoduodenectomy, remain controversial. The fact that a variety of reconstruction methods have been described for providing bowel and biliary tract continuity after Whipple's operation, can be noted as an indicator of the controversial situation in this area, depending on postoperative complication ratios of the surgical procedures.

The main reason for different reconstruction methods emergening, is the reduction of post-operative complications observed after Whipple's operation. For this purpose, different types of pancreaticojejunostomy or gastrojejunostomy methods have been proposed, and advantages and disadvantages of these surgical methods have been compared. It is observed that single loop jejunal reconstructions have significant advantages, in terms of protection of the anastomotic line, and reduction of anasto- motic leaks when compared with Roux and $\mathrm{Y}$ jejunal reconstructions. Along with that, DGE is the most common complication observed after pancreaticoduodenectomies. ${ }^{4-6,10}$ It is shown that DGE incidence is not affected by implementation of pylorus-preserving or standard Whipple procedure. ${ }^{4}$ Gastrojejunal anastomosis in reconstruction is usually performed last, and placed approximately $40 \mathrm{~cm}$ distal to biliary anastomosis for the purpose of neutralization of gastric-acid secretion. We realized a modified reconstruction by performing proximal gastrojejunal anastomosis between pancreaticojejunostomy and hepaticojejunostomy on a jejunal loop, after Whipple's procedure in our technique. Post-operative pancreatic fistula which occured following post-operative acute pancreatitis. was observed in only 1 patient, and treated with medical intervention.

DGE was not observed in our patients, except postoperative acute pancreatitis and pancreatic fistula developing in a patient. One of the our patients had wound infection and detachment, and we did not encounter intaabdominal hemorrhage or abscess in our series. No marginal ulceration was detected in our patients who underwent modified reconstruction, in their repeated post-operative gastroduodenoscopic examinations, and this condition can be noted as no significant relationship between marginal ulceration and proximalization of gastrojejunostomy. We are uncertain about causes of DGE in the patient, and whether causes occured subsequent to pancreatic fistula. Although the number of cases in our series is insufficient for detailed evaluation, a modified reconstruction on a jejunal loop by proximalizing the gastrojejunostomy is a safe method, and seems to have some advantages, in terms of major complications of Whipple's procedure.

\section{REFERENCES}

1. Artinyan A, Soriano PA, Prendergast C, Low T, Ellenhorn JD, Kim J. The anatomic location of pancreatic cancer is a prognostic factor for survival. HPB (Oxford) 2008;10:371-376.

2. Whipple AO, Parsons WB, Mullins CR. Treatment of carcinoma of the ampulla of Vater. Ann Surg 1935;102:763-779.

3. Kausch W. Das carcinom der papilla duodeni und seine radikale Entfernung. Beitr Z Klin Chir 1912;78:439-486.

4. Gouma DJ, van Geenen RC, van Gulik TM, de Haan RJ, de Wit LT, Busch OR, et al. Rates of complications and death after pancreaticoduodenectomy: risk factors and the impact of hospital volume. Ann Surg 2000;232:786-795. 
5. Fabre JM, Burgel JS, Navarro F, Boccarat G, Lemoine C, Domergue J. Delayed gastric emptying after pancreaticoduodenectomy and pancreaticogastrostomy. Eur J Surg 1999;165: 560-565.

6. Parmar AD, Sheffield KM, Vargas GM, Pitt HA, Kilbane EM, Hall BL, et al. Factors associated with delayed gastric emptying after pancreaticoduodenectomy. HPB (Oxford) 2013;15:763-772.

7. Romano G, Agrusa A, Galia M, Di Buono G, Chianetta D, Sorce $\mathrm{V}$, et al. Whipple's pancreaticoduodenectomy: surgical technique and perioperative clinical outcomes in a single center. Int J Surg
2015;21 Suppl 1:S68-S71.

8. Saraee A, Vahedian-Ardakani J, Saraee E, Pakzad R, Wadji MB. Whipple procedure: a review of a 7-year clinical experience in a referral center for hepatobiliary and pancreas diseases. World J Surg Oncol 2015;13:98.

9. Søreide K, Labori KJ. Risk factors and preventive strategies for post-operative pancreatic fistula after pancreatic surgery: a comprehensive review. Scand J Gastroenterol 2016;51:1147-1154.

10. Ho CK, Kleeff J, Friess H, Büchler MW. Complications of pancreatic surgery. HPB (Oxford) 2005;7:99-108. 